\title{
Differential Talent Test and Lee-Thorpe Interest Test: Study of Predictive Validity in Specialization of High School Students
}

\author{
Nikon Aritonang ${ }^{1 *}$, I NyomanDegeng ${ }^{2 *}$, Triyono, M. Ramli ${ }^{3}$ \\ nickari333@gmail.com, nyoman.sudana.d.fip@um.ac.id \\ ${ }^{1,2,3)}$ Counseling Guidance Study Program, Postgraduate, State University of Malang, Indonesia \\ *nickari333@gmail.com
}

\begin{abstract}
The purpose of this study is to conduct research on the predictive validity of the differential aptitude test and the Lee-Thorpe interest test towards students' interest in career decision making. Predictive validity studies used to provide test information and which subjects have significant predictive value in choosing students' interests according to their talents and interests. The sample of this study was 349 high school students in Malang. Data collection instruments used were differential aptitude tests and Lee-Thorpe interest tests. The data analysis technique used is binominal logistic regression. The research method used is a survey, which is a study that takes samples from the population and uses the differential aptitude test instrument and the Lee-Thorpe interest test as a data collection tool. Based on the results of the research and assessment tests conducted, it found that many students in the chosen specialization did not match their talents and interests and potential. This problem will harm the selection of majors in college and career decision making that is not right so that it will produce low-quality Human Resources. The first factor influencing the choice of specialization is the students' lack of understanding of their talents and interests. Then the second factor that influences the selection system of specialization is not quite right. While the third factor that influences is not done narrative counseling to students, before making specialization choices, as a result of the factors that influence the mistakes in the choice of specialization, students make a selection based on a sense of security, choosing majors that do not have many counting subjects or are related to numbers, then feel amazed at a particular profession even though it is not in accordance with their talents and interests, and suggestions or suggestions from people around him because students do not understand their talents and interests and abilities, so they follow what their parents and friends suggest.
\end{abstract}

Keywords: talent and interest; selection, career, decision making

\section{Introduction}

One of the essence and impact of the industrial era 4.0 is the problem of human resources, especially one's career, and performance on the needs of a good or superior quality workforce. For this reason, the Indonesian government has a program to meet the needs of the qualified workforce with the slogan "Superior Human Resources (HR), developed countries." This slogan is not just a word on the lips, but it will be done and achieved. Having superior human resources is an asset of the nation and country which is very expensive, superior is not just 
smart in the value of education, but various aspects of life, so that it can face competition in ASEAN countries and globally.

The description of the quality of education in ASEAN in the context of compatibility and readiness of high school graduates with the world of work is around $40 \%$ while at the university level, the average graduate skills are around 53-58\%. In Indonesia, high school graduates who are ready and fit to enter the workforce are around 35\% and Singapore 70\% more. The same comparison also occurs at the S1 level, in Singapore, reaching $80 \%$ while Indonesia is only $40 \%$ [1].

The low readiness and suitability of the world of work with high school graduates and tertiary education graduates in Indonesia are most likely due to an incorrect choice of specialization when entering the tenth grade. Every student, when entering a new teaching and higher level from junior high school to senior high school, has to set a specialization field. Many schools do not have standard guidelines and directions for students to determine the right direction, so the school submits to students personally, even though students do not have the preparation and ability to make the right choice according to their talents and interests. Faced with these confusing situations and conditions, many students make specialization choices based on security, admiration for a career field, and what their parents or friends say.

Errors in decision making specialization in high school (SMA) will significantly influence the selection of majors in tertiary institutions (PT) and harm motivation to complete college or make improper career decisions. It is a complicated decision for students because it determines the type of profession that suits their talents and interests [2]. Making the right specialization decisions that match your talents and interests are the keys or the primary factors driving the spirit in each individual to be able to achieve success in study and work. Benneth in Pali [3] said the Differential Talent Test designed to use in educational counseling for high school-age students.

The phenomenon of high school graduates who enter tertiary institutions, many of which have not based on specialization direction. Supported by optimal potential and self condition, such as basic abilities (intelligence), talent interests, and physical and social and cultural conditions and the right career. For the continuation of the students' willingness so far, they are more likely to choose based on the wishes of their parents, economic considerations, and the learning outcomes they have taken. As a result, after being in college, they often experience learning difficulties, fall into various forbidden behaviors and personal problems, so they do not move up, move majors/study programs, move education units/colleges, and even drop out $[4,5,7]$.

\section{Research Method}

The title of this research is "Differential Talent Test and Lee-Thorpe Interest Test: Study of Predictive Validity in Specialization of High School Students in Malang City." The research method used is survey research, which is research that takes samples from the population and uses the instrument of talent and interest as a means of collecting data.

Based on the results of relevant literature studies, this research makes the career decision making of high school students as the object of research. Factors thought to influence career decision making, including talent and interest. Based on the operational definition of talent and interest can be explained as follows:

a) Talent is the ability possessed by someone to produce an achievement with high motivation and pleasure in doing work. 
b) Interest is the feeling of pleasure that someone has in doing a line of work.

This study divides two variables, namely endogenous variables (Y) and exogenous variables (X). Endogenous variables in question are variables that are influenced by other variables. Exogenous variables are variables that can affect other variables. Career decision making is an endogenous variable, and exogenous variables in this study are talent and interest.

The population in this study were state high school students in Malang. The sample or part of the population under study has the same characteristics as the population. The sample is part of a population that is carefully chosen to represent the population [8] The sample must represent the population because, based on studies conducted on the sample, the researcher will draw conclusions that will be generalized to the population [9]. This study used a sample of 349 state high school students in Malang, divided into science majors and social studies majors.

\section{Types and Data Sources}

The type of data used in this study is interval data and nominal data. Sources of data in this study include primary data sources because they were taken directly from poor high school student respondents through questionnaires.

\section{Data Analysis Methods}

The data analysis method in this study divided into several stages. First, the questionnaire data from high school student respondents obtained from the differential aptitude test and the Lee-Thrope position interest test are encrypted based on PP scores (percentile points). This category divided into low, medium, and high. Second, categorized PP data is processed through descriptive statistics to determine the modes presented in the form of the frequency distribution. The last step is the data processed using the binominal regression test. The binominal logistic regression test can be used to look for the influence of exogenous variables with categories greater than two or polychotomous. Exogenous variables can scale ratio, interval, ordinal, and categorical [10]. Processing data in statistics using SPSS 21 software for Windows.

\section{Results and Discussion}

Data obtained from the results of the differential aptitude test and interest test of LeeThorpe's position, which have formed a nominal scale, were processed statistically. The distribution of percentile points (PP) values from the dimensions of talent and areas of interest-based on the magnitude of the value obtained (high-medium-low) on students majoring in Natural Sciences and students majoring in Social Sciences presented in tables based on the number and percentage. Data based on the value of PP (high-medium-low) from the dimensions of talent and areas of interest can see from the frequency distribution of students majoring in Natural Sciences and Social Sciences who have taken the test.

Table 1.1 above shows the dimensions of verbal talent at the low-value level had the highest number both in the science majors at $57.2 \%(\mathrm{n}=107)$ and social science majors at $67.3 \%(\mathrm{n}=109)$. The second-highest number was at a moderate level at $24.1 \%$ in the science department $(n=45)$ and the social science department $(n=39)$. The highest value level of verbal talent dimensions in the science department was $18.7 \%(n=35)$ and the social science department, with a percentage of $8.6 \%(n=14)$. 
Table 3.1 Frequency Distribution of Dimensions of Talent among Students of the Department of Natural Sciences and Department of Social Sciences

\begin{tabular}{|c|c|c|c|c|c|c|c|c|c|c|c|c|c|}
\hline \multirow{4}{*}{ No } & \multirow{4}{*}{$\begin{array}{c}\text { Dimension } \\
\text { of Talent }\end{array}$} & \multicolumn{12}{|c|}{ Department } \\
\hline & & \multicolumn{6}{|c|}{ Natural Sciences } & \multicolumn{6}{|c|}{ Social Sciences } \\
\hline & & \multicolumn{2}{|c|}{ Low } & \multicolumn{2}{|c|}{ Medium } & \multicolumn{2}{|c|}{ High } & \multicolumn{2}{|c|}{ Low } & \multicolumn{2}{|c|}{ Medium } & \multicolumn{2}{|r|}{ High } \\
\hline & & $\mathrm{n}$ & $\%$ & $\mathrm{n}$ & $\%$ & $\mathrm{n}$ & $\%$ & $\mathrm{n}$ & $\%$ & $\mathrm{n}$ & $\%$ & $\mathrm{n}$ & $\%$ \\
\hline 1 & Verbal & 107 & 57.2 & 45 & 24.1 & 35 & 18.7 & 109 & 67.3 & 39 & 24.1 & 14 & 8.6 \\
\hline 2 & Numeric & 27 & 14.4 & 62 & 33.2 & 98 & 52.4 & 97 & 59.9 & 49 & 30.2 & 16 & 9.9 \\
\hline 3 & Abstract & 46 & 24.6 & 75 & 40.1 & 66 & 35.3 & 83 & 51.2 & 56 & 34.6 & 23 & 14.2 \\
\hline 4 & Mechanic & 68 & 36.4 & 66 & 35.3 & 53 & 28.3 & 88 & 54.3 & 53 & 32.7 & 21 & 13 \\
\hline 5 & $\begin{array}{l}\text { Space } \\
\text { Relations }\end{array}$ & 21 & 11.2 & 46 & 24.6 & 120 & 64.2 & 50 & 30.9 & 49 & 30.2 & 63 & 38.9 \\
\hline 6 & $\begin{array}{l}\text { Speed and } \\
\text { Clerical } \\
\text { Accuracy } \\
\text { (SCA) }\end{array}$ & 30 & 16 & 94 & 50.3 & 63 & 33.7 & 57 & 35.2 & 87 & 53.7 & 18 & 11.1 \\
\hline
\end{tabular}

In the numerical aptitude dimension with a high-level score, the science department has the highest percentage, with $52.4 \%(\mathrm{n}=98)$, followed by a low level with $33.2 \%$ and a low level of $14.4 \%$. The Department of Social Sciences has the highest number at the low level of $59.9 \%(n=97)$, and the medium level of $30.2 \%(n=49)$, and the high-level value of the numerical dimension is $9.9 \%(n=16)$. The most scores on abstract talent dimensions in the natural science majors were at the moderate level with $40.1 \%(n=75)$ and different from the social science majors at the low level of $51.2 \%(n=83)$. The highest number of dimensions of mechanical talent was at a low level in both majors, namely the science department with $36.4 \%(n=68)$ and the social science department with $54.3 \%(n=88)$. The Department of Natural Sciences and the Department of Social Sciences gained a large percentage of the dimensions of space relation talent at a high-value level, namely $64.2 \%(n=120)$ and $38.9 \%$ $(n=63)$. The KKK talent dimension that emerged in the IPS department with a high level was $11.1 \%$ and the science department at the same level, with a percentage of $33.7 \%(n=63)$.

Table 3.2 Frequency Distribution of Interest Fields among Students of the Department of Natural Sciences and Department of Social Sciences

\begin{tabular}{|c|c|c|c|c|c|c|c|c|c|c|c|c|c|}
\hline \multirow{4}{*}{ No } & \multirow{4}{*}{ Interest Field } & \multicolumn{12}{|c|}{ Department } \\
\hline & & \multicolumn{6}{|c|}{ Natural Sciences } & \multicolumn{6}{|c|}{ Social Sciences } \\
\hline & & \multicolumn{2}{|c|}{ Low } & \multicolumn{2}{|c|}{ Medium } & \multicolumn{2}{|c|}{ High } & \multicolumn{2}{|c|}{ Low } & \multicolumn{2}{|c|}{ Medium } & \multicolumn{2}{|c|}{ High } \\
\hline & & $\mathrm{N}$ & $\%$ & $\mathrm{n}$ & $\%$ & $\mathrm{n}$ & $\%$ & $\mathrm{n}$ & $\%$ & $\mathrm{n}$ & $\%$ & $\mathrm{n}$ & $\%$ \\
\hline 1 & Personal Social & 49 & 26.2 & 43 & 23 & 95 & 50.8 & 31 & 19.1 & 31 & 19.1 & 100 & 61.7 \\
\hline 2 & Natural & 98 & 52.4 & 49 & 26.2 & 40 & 21.4 & 81 & 50 & 43 & 26.5 & 38 & 23.5 \\
\hline 3 & Mechanic & 153 & 81.8 & 23 & 12.3 & 11 & 5.9 & 123 & 75.9 & 27 & 16.7 & 12 & 7.4 \\
\hline 4 & Bussiness & 70 & 37.4 & 47 & 25.1 & 70 & 37.4 & 28 & 17.3 & 53 & 32.7 & 81 & 50 \\
\hline 5 & Art & 113 & 60.4 & 41 & 21.9 & 33 & 17.6 & 71 & 43.8 & 49 & 30.2 & 42 & 25.9 \\
\hline 6 & Siences & 114 & 61 & 39 & 20.9 & 34 & 18.2 & 119 & 73.5 & 29 & 17.9 & 14 & 8.6 \\
\hline
\end{tabular}

Source: Statistical data processing 
Based on table 1.2, the social, personal talent field at the high-value level has the highest number both in the natural sciences major at $50.8 \%(\mathrm{n}=95)$ and the social sciences major at $61.7 \%(\mathrm{n}=100)$. The second-highest number was in the medium and low levels in the Social Sciences majors, each at $19.1 \%(\mathrm{n}=31)$. The level of moderate and low value in the field of personal social interest in the Department of Natural Sciences is $23 \%(n=43)$ and $26.2 \%(n=$ 49). In the area of natural interest, the Department of Natural Sciences has a percentage of $52.4 \%(\mathrm{n}=98)$ at the low level, followed by a moderate level with $26.2 \%(\mathrm{n}=49)$ and a high level of $21.4 \%(\mathrm{n}=40)$. The Social Sciences Department has the highest number at the low level of $50 \%(n=81)$, and the moderate level of $26.5 \%(n=43)$ and the high-level score in the natural talent field is $23.5 \%(\mathrm{n}=38)$. The value in the field of mechanical interest was mostly in the science department at a low level, with a total of $81.8 \%(\mathrm{n}=153)$, and the same was the case for the social science department at a low level of $51.2 \%(n=83)$. The total number of dimensions of business interest is at a low level and high level in the science department, which is $37.4 \%(n=70)$. The Social Sciences Department has the two most significant percentages of business interest, namely $50 \%(\mathrm{n}=80)$ at the high-grade level and $32.7 \%(\mathrm{n}=$ 53). The Department of Natural Sciences and the Department of Social Sciences get a large percentage for the field of interest in art at a low-value level, namely $60.4 \%(n=113)$ and $43.8 \%(n=71)$. The field of scientific interest that emerged in the Social Sciences department with a high level of $8.6 \%(n=14)$ and a low level reached $73.5 \%(n=119)$. The Department of Natural Sciences in the field of interest in science with scores at a low level classified as many with a percentage of $33.7 \%(n=3)$ and grades at a high level only reach $18.2 \%(n=34)$.

The statistical test used in this study is a binominal logistic regression test that intended to determine the predictor variables and response variables that are interrelated and influence the interest of high school students in career decision making. In this study, there is a coefficient of the relationship from exogenous to endogenous. The coefficient is a value which if the value of the predictor variable (influences) changes, will cause a change in the response variable (influenced). If the coefficient value is positive, it means that if the predictor variable increases, the response variable will also increase and vice versa. If the coefficient value is negative, it means that if the predictor variable increases, the response variable will decrease. The logistic regression method expressed in a probability model, which is a model in which the dependent variable is the logarithm of the probability that an attribute will apply under conditions of certain independent variables. To test the significance of the coefficients of the model that been obtained, then the following hypothesis test is carried out;

The simultaneous test used to check the function of the coefficient $\beta$ together to test the Likelihood Ratio method. For example, Y1, Y2, Y3... YT is a random variable that is independent of $\mathrm{T}$, each of which has a probability distribution function $\mathrm{f}(\mathrm{Yt} ; \beta 1, \beta 2, \beta 3 \ldots, \beta \mathrm{p})$ for $\mathrm{t}=1,2,3, \ldots, \mathrm{T}$. a set consisting of all point parameters $(\beta 1, \beta 2, \beta 3 \ldots, \beta \mathrm{p})$. Denoted by $\beta$ and $\omega$. The set of Hypothesis concurrent tests is as follows.

$\mathrm{H} 0: \beta 1=\beta 2=\beta 3 \ldots=\beta p=0$

$\mathrm{H} 1$ : at least there is one that is not equal to zero, $\mathrm{j}=1,2,3, \ldots, \mathrm{p}$.

Test statistics used are as follows.

Here :

$$
\mathrm{G}=-2 \operatorname{Ln} \frac{\mathrm{L}(\omega)}{L(\beta)}
$$

$\mathrm{L}(\omega)=$ maximum likelihood value without certain predictor variables.

$\mathrm{L}(\beta)=$ maximum likelihood value with certain predictor variables. 
H0 rejected if the $p$-value $\leq \alpha(0.05)$, which means that there is one or more $\beta$ that has a significant effect on the response variable.

Table 3.3 Binomial Logistic Regression Statistical Tests

\begin{tabular}{llcccc}
\hline \multirow{2}{*}{ Construct } & \multicolumn{1}{c}{ Variable } & \multirow{2}{*}{ Coefisien B } & P value & \multicolumn{2}{c}{ 95\% C.I.for EXP(B) } \\
& & & & Lower & Upper \\
\hline Talent & VERBAL & -0.280 & 0.294 & 0.448 & 1.276 \\
& NUMERIC & 1.072 & 0.000 & 1.713 & 4.980 \\
& MECHANICAL. TALENT & 0.200 & 0.315 & 0.827 & 1.801 \\
& ABSTRACT & 0.234 & 0.247 & 0.850 & 1.881 \\
& RELATIONSHIPS & 0.175 & 0.389 & 0.800 & 1.775 \\
& SCA & 0.800 & 0.000 & 1.422 & 3.481 \\
\hline Interest & PERSONAL. SOCIAL & -0.173 & 0.330 & 0.595 & 1.190 \\
& NATURAL & -0.456 & 0.018 & 0.434 & 0.925 \\
& MECHANICAL. INTEREST & -0.881 & 0.001 & 0.246 & 0.697 \\
& BUSINESS & -0.804 & 0.000 & 0.299 & 0.671 \\
& ART & -0.532 & 0.005 & 0.405 & 0.852 \\
& SCIENCE & 0.265 & 0.224 & 0.850 & 1.997 \\
\hline R Square & 0,481 & & & & \\
\hline
\end{tabular}

Source: Statistical data processing

The calculation results show that from the aspect of talent that has a significant effect ( $\mathrm{p}$ $<0.05$ ) on the selection of natural science majors, there are two significant, namely numerical ( $p$-value $=0,000)$ and KKK $(p=0,000)$. Whereas the aspects of interest that have a significant effect are 4 namely Natural $(p=0.018)$, Mechanical interest $(p=0.001)$, Business $(p=0,000)$ and Art $(\mathrm{p}=0.005)$. From these results, it shows that the factor most considered in the selection of natural science majors is interest over talent. Talent considered two variables, while interest is four variables. It shows that talent is not a consideration in choosing a science major; students consider their interests more.

Factors that encourage students to choose science majors are numerical ability and SCA. The coefficient calculation results obtained that the numerical and SCA have a positive effect. The positive influence means that the higher the numerical ability and KKK, the students will choose the science department. Theoretically, numerical variables are appropriate variables in the selection of natural science majors. However, the KKK is not a necessary factor for the selection of natural science majors. KKK needed in the selection of Social Science majors.

The results of calculations on aspects of interest that natural abilities, mechanical interests, business, and art negatively affect. It means that the higher the natural abilities, the mechanical interests, the business, and the art, the more they choose to major in social studies. Theoretically, the skills needed for social studies majors are business. While natural, mechanical interests, art is more appropriate to choose a science major. With this result, only two variables are the basis of accuracy in choosing a science or social science major, namely numerical for natural science and business for social science. Besides that, there was an inaccuracy. It shows that they chose majors based on their desires, influenced by the environment, and a sense of security, not based on their talents and interests. Therefore, between talent and interest with the chosen majors is not right. Students with natural interests, mechanical interests, and art prefer Social Science even though the interest is more appropriate for natural science majors. 
Errors in the selection of student majors mentioned above is a picture of a very urgent problem, where students will choose the majors in college. Mistakes in the selection of majors at University have an impact on students; it will be difficult to finish college and cause psychological problems. Besides, students who can complete their studies find it difficult to get a job because of the skill level and suitability of scientific disciplines that are not competent with the workforce needs. Therefore it will be difficult to find superior human resources and unable to compete with workers from abroad.

The government is very urgent to improve student career decision making systems in this case specialization in high school to anticipate that the negative impact on Indonesian Human Resource will not be greater.

\section{Conclusion}

Making career decisions of students that are not following the talents of their interests will have a significant impact on students, parents, labor users, and the country. The effect that occurred was not when they made their decision when they were in the first year of high school, but after they had gone through several years later, both were still sitting on the school bench and in university. But the fatal impact is that after they work, they will quickly experience boredom because they do not enjoy work, and will often change their jobs.

The impact of student career decision-making errors will result in low human resources that are suitable for work skills, so that labor users will experience less than optimal work processes, due to high turnover rates. Besides, the workforce lacks motivation and creativity because workers only do and earn money, not because they enjoy work.

Difficult to get superior human resources, due to career decision making mistakes in high school, students do not understand their talents of interest and potential when making specialization choices, making it more easily influenced by parents and friends. For this reason, the teacher's role in career counseling is urgently needed and needs to test talent interests and potential first.

\section{References}

[1] ILO-Asia Pacific Working Paper. (2014), Survey of ASEAN Employers on Skills and Competitiveness, Bangkok: International Labour Organization.

[2] Shezi, S. E. (2013). Factors that Influence University Career Decision. Dissertation submitted in partial fulfillment of requirements for the degree of master of art. Psychology Department at the University of Zululand.

[3] Pali, Marthen. (2017), Materi Pelatihan 4 Tes Kemampuan Khusus: Bakat, Malang: UniversitasNegeri Malang.

[4] Pali, Marthen. (1993), Tes Matriks Progressif Dan Test Bakat Diffrensial: Studi Validitas Prediktif Prestasi Belajar Siswa SMA dan Validitas Sintetik pada Tiga Jenis Pekerjaan. Disertasi Program Pascasarjana, Universitas Indonesia.

[5] Otta E.F, and Njoku, W. Ikwuonu. (2014), Self Concept and Vocational interest among secondary school student; Foundation, Faculty of education State University, Uturu, Nigeria. 
[6] Brown, D. S. and Lent, W. R. (2013), Career Development and Counseling. Canada: John Wiley \& Sons.

[7] Asosiasi Bimbingan dan Konseling Indonesia (ABKIN). (2014), Panduank Khusus Bimbingan dan Konseling Pelayanan Arah Peminatan Peserta Didik. Jakarta: ABKIN.

[8] D. R. Cooper, C. W. Emory. (1995), Business Research Methods, 5th Edition, Irwin.

[9] Sekaran, U. (2000), Research Methods for Business: A Skill Business Approach. New York: John Wiley \& Sons.

[10] Field, Andy. (2005). Discovering Statistics Using SPSS for Windows: Advanced Techniques for the Beginning, London: Sage Publication. 